\title{
REVISED Estrogen as Jekyll and Hyde: regulation of cell death
}

\section{[version 2; peer review: 2 approved]}

\author{
Wen Zhou'1,2, Xiaoxia Zhu \\ ${ }^{1}$ Braman Family Breast Cancer Institute, University of Miami Sylvester Comprehensive Cancer Center, University of Miami Miller \\ School of Medicine, Miami, Fl 33136, USA \\ 2Department of Biological Sciences, Columbia University, New York, NY, 10027, USA \\ ${ }^{3}$ Molecular Oncology Program, Division of Surgical Oncology, Dewitt Daughtry Family of Surgery, University of Miami Miller School \\ of Medicine, Miami, FI 33136, USA
}

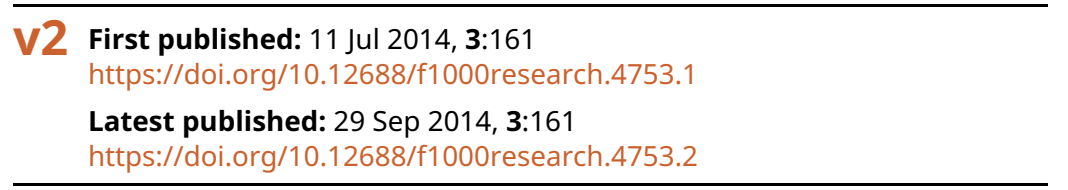

\section{Abstract}

Sustained estrogenic exposure increases the risk and/or the progression of various cancers, including those of the breast, endometrium and ovary. Unexpectedly, physiological level of estrogen together with a novel IKKa inhibitor BAY11-7082 could effectively induce cell apoptosis in ER-positive breast cancer cells, suggesting combining estrogen with IKKa inhibition may be beneficial for breast cancer patients. This opinion article touches upon the dual role estrogen played in inducing cancer cell death and asks whether use of estrogen in combination with IKKa-targeted therapy would be possible reconsider the newly identified crosstalk between ER and NFK $B$ pathway which can be utilized to switch the effects of estrogen on cell death.

Keywords

17ß-estradiol, breast cancer, apoptosis, IKKa, BAY11-7082

Open Peer Review
Approval Status
version 1
11 Jul 2014
(revision)
1. Steven L..............................................................
at Chapel Hill, Chapel Hill, NC, USA
2. Philippa Saunders 2014
Edinburgh, Edinburgh, UK
Any reports and responses or comments on the
article can be found at the end of the article.

\section{Corresponding author: Wen Zhou (wz2313@columbia.edu)}

Competing interests: No competing interests were disclosed.

Grant information: This work was partially supported by US Department of Defense pre-doctoral grant W81XWH-11-1-0097 (W.Z.). The funders had no role in study design, data collection and analysis, decision to publish, or preparation of the manuscript.

Copyright: ( 2014 Zhou W and Zhu X. This is an open access article distributed under the terms of the Creative Commons Attribution License, which permits unrestricted use, distribution, and reproduction in any medium, provided the original work is properly cited. Data associated with the article are available under the terms of the Creative Commons Zero "No rights reserved" data waiver (CC0 1.0 Public domain dedication).

How to cite this article: Zhou W and Zhu X. Estrogen as Jekyll and Hyde: regulation of cell death [version 2; peer review: 2 approved] F1000Research 2014, 3:161 https://doi.org/10.12688/f1000research.4753.2

First published: 11 Jul 2014, 3:161 https://doi.org/10.12688/f1000research.4753.1 


\section{REVISED Amendments from Version 1}

The authors would like to thank the referees for the helpful and constructive critiques of the manuscript. The observations made by the referees were very helpful and we have adapted the manuscript according to their suggestions. We have rewritten part of the introduction, including the part Dr Young pointed out, and added more discussion on Perillo's article in the body of the text.

See referee reports

\section{Introduction}

Our research projects currently focus on the understanding of the interplay between different signaling cascades and estrogen receptor alpha (ER) dependent transcription activation in breast cancer. $\mathrm{ER}$ is a master transcription factor frequently elevated in breast cancer patients. ER-positive breast cancers usually occur in up to two thirds of newly diagnosed breast cancer patients. Drugs (such as the antiestrogens tamoxifen and raloxifene) have been very effective in treating ER-positive breast cancers and have saved millions of lives. However, this standard treatment does not work for all ER-positive breast cancer patients. Therefore, we enthusiastically review recent research breakthroughs in the context of our ever-developing understanding on ER function. These new mechanistic insights on the crosstalk between ER and NFKB pathway will lay the ground work for improved clinical approaches to the treatment of this type of breast cancer.

For many years, those of us working in the field were used to looking at estrogen as a mitogen through its genomic function mediated by ER-dependent transcription program. Now we realize that estrogen through ER, in addition to regulating gene expression, crosstalks with many non-genomic signaling pathways involved in cell growth, differentiation and apoptosis. These newly identified interplays may give a different flavor to long conceived mitogenic role of estrogen. In this opinion article, we generally reviewed the changing attitude toward the use of estrogen in the clinic, with a focus on newly discovered pro-apoptotic roles of estrogen when combined with IKK $\alpha$ inhibitors. We also discussed the possibility of estrogen and IKK $\alpha$ inhibitor dual-therapy in ER-positive breast cancer treatment.

\section{Historical perspectives: changing attitudes toward the use of estrogen in the clinic}

Sir George Thomas Beatson (1896) use oophorectomy to reduce estrogen level in premenopausal women in order to prevent breast cancer occurrence. It was for the first time to reveal the mitogenic role of estrogen at physiological concentration ${ }^{1}$. Half a century later, Haddow et al. (1944) firstly used a high-dose estrogen to induce tumor regression of hormone-dependent breast cancer in postmenopausal women ${ }^{2}$. Therefore, the effect of estrogen is dose-dependent, and thus it is important to take into account the hormonal status of women (pre- or postmenopausal). Huggins et al. (1952) pioneered adrenalectomy to reduce estrogen level for treating mammary cancer ${ }^{3}$. Huggins' work is internationally recognized by the most prestigious Nobel Prize (1966) for the contribution in the development of endocrine therapy in hormone-regulated cancer. Elwood
Vernon Jensen (1958) characterized the first receptor for estrogen - estrogen receptor alpha. Soon after these discoveries, extensive mechanistic studies have gained large information about estrogen's physiological functions and carcinogenic roles. The Women's Health Initiative research program (1991) initiated a 15-year study enrolled 161,808 generally healthy women aged $50-79$ to evaluate the beneficial effects of postmenopausal hormone replacement therapy on heart diseases, bone fractures, and cancers ${ }^{4}$. Due to the increased incidence of breast cancer, stroke, and cardiovascular complications in women treated with estrogen alone or with a combination of estrogen and progesterone, the study was terminated prematurely in 2002. Though extensively studied, the definite understanding of the mechanism of estrogen action always challenges our mind.

The challenge: paradoxical role of estrogen in cell death Estrogen regulates the proliferation and development of tissues expressing estrogen receptors and ER is mainly expressed in breast epithelium, ovary and endometrium. Thus, estrogen is mitogenic for cultured ER positive breast cancer lines. The mitogenic effects of estrogen at the G1-to-S transition are mediated by the key effectors of estrogen action, c-Myc, cyclin D1 and E2F-1 ${ }^{5-7}$. c-Myc expression occurs within $15 \mathrm{~min}$ of estrogen stimulation, among the earliest responses to estrogen. Estrogen also rapidly induces cyclin D1 expression. In the G1 phase, estrogen drives E2F-1 expression. Nongenomically, Estrogen binding to the ER stimulates rapid activation of Src and signaling pathways MAPK and PI3K/Akt pathways that affect cell survival ${ }^{8,9}$. Based on these understandings of estrogen action, ER protein is assayed in newly diagnosed breast cancers because it is a clinically useful prognostic factor and predicts responsiveness to ER blocking drugs such as Tamoxifen.

Paradoxically, estrogen induces apoptosis under certain circumstances. As aforementioned, high-dose estrogen was used to induce tumor regression of hormone-dependent breast cancer in postmenopausal women before the introduction of tamoxifen ${ }^{2}$. This regimen is of clinical interest, given that long-term treatment of breast cancer with the antiestrogen tamoxifen often leads to drug resistance and that sustained tamoxifen exposure may sensitize breast cancer cells to estrogen therapy ${ }^{10}$. The field of the mysterious dual effects of estrogen on apoptosis has not much progress until recently.

\section{Research breakthrough}

Perillo Group from the Second University of Naples identified a key player, IKK $\alpha$ in the switch of estrogen action in apoptosis ${ }^{11}$. They found ER agonist 17 $\beta$-estradiol (E2) and IKK $\alpha$ kinase specific inhibitor BAY11-7082 (BAY) in combination can induce apoptosis in $\mathrm{ER} \alpha$ positive breast cancer cell line, and dual-therapy now receives more and more attention.

In the journal Cell Death \& Differentiation, Perillo et al. recently reported that the inhibition of IKK $\alpha$ by BAY switched the effect of estrogens on breast cancer cells from anti- to pro-apoptotic, which leads the exploration of therapeutic benefits of estrogen into a new era ${ }^{11}$. IKK $\alpha$ is the kinase responsible for histone H3 Ser 10 phosphorylation $(\mathrm{H} 3 \mathrm{pS} 10)^{12}$. H3pS10 is known to inhibit H3 Lys 9 dimethylation $(\mathrm{H} 3 \mathrm{~K} 9 \mathrm{me} 2)$ in a space repulsion model ${ }^{13}$. Thus, inhibiting $\mathrm{H} 3 \mathrm{pS} 10$ by targeting IKK $\alpha$ facilitates estrogen-triggered 
ER-dependent recruitment of histone methyltransferase Suv39H1. Histone demethylase LSD1 demethylating the Suv39H1 target sites H3K9me2 was increased concomitantly. LSD1-mediated demethylation process is known to produce reactive oxygen species (ROS) and cause ROS-mediated DNA damaging effects ${ }^{14}$. The net results after IKK $\alpha$ knowndown is causing more DNA damages to cancer cells through estrogen triggered ER-dependent Suv39H1 and LSD1 binding to ER target gene promoter (Figure 1).

In short, Perillo group identifies a novel crosstalk between IKK $\alpha$ and estrogen signaling and shows that inhibition of IKK $\alpha$-mediated histone phosphorylation switch ER-mediated anti-apoptotic effects to ER-dependent ROS-mediated breast cell death, which implicates potential dual-therapy of ER agonist (E2) together with IKK $\alpha$ inhibitor (BAY) in a variety of hormone-regulated cancers. Questions remain as to whether this study using tissue-culture adapted

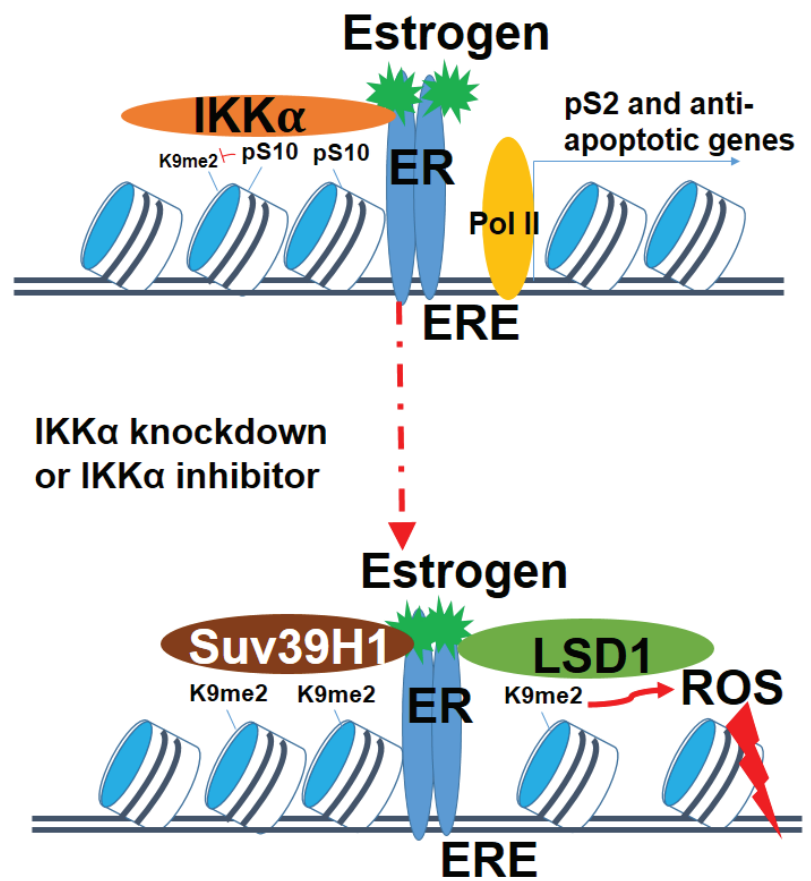

Figure 1. Involvement of IKK $\alpha$ in estrogen-triggered ER-dependent activation of the $\mathbf{p S 2}$ promoter. Upper panel: chromatin landscape and factors present at the pS2 (as known as TFF1) promoter in the presence of IKK $\alpha$. The pS2 promoter is enriched with nucleosomes (blue and white cylinders) that dwell in positions proximal to the transcription start site ( +1 position) and at ER binding sites. Only low levels of histone $\mathrm{H} 3$ lysine 9 dimethylation (H3K9me2) exist due to the space repulsion of histone methyltransferase from IKK $\alpha$ residing at the neighboring $\mathrm{H} 3 \mathrm{~S} 10$ site. RNA polymerase holoenzyme (Pol II) (yellow oval) is present at the proximal promoter region near the transcription start site (TSS, shown by black vertical line) of the pS2 gene. Lower panel: chromatin landscape and factors present at pS2 promoter following IKK $\alpha$ knockdown or IKK $\alpha$ inhibitor BAY11-7082 treatment. Once levels of IKK $\alpha$ have decreased, ER recruits the histone methyltransferase Suv39H1 or demethylase LSD1 proteins to bind within the pS2 promoter. Once the LSD1 is activated and demethylates its target $\mathrm{H} 3 \mathrm{~K} 9 \mathrm{me} 2$, it generates reactive oxygen species (ROS) to cause DNA damage effects including base oxidation and nicks results from DNA damage itself and related DNA repair. In sum, the inhibition of IKK $\alpha$ results in the reversion of estrogen triggered anti-apoptotic effects to pro-apoptotic effects. cell lines such as MCF-7 is relevant to clinic practice. The consideration here is mainly based on the well documented limitations of using established cell lines to predict a clinical response, with several compounds that show dramatic tumor killing in cell models failing to yield clinical benefits. Given that established cell lines do not fully reflect the genomic heterogeneity we now appreciate existing in different breast tumors, it will be important to test the same drug combination in a more clinical-relevant sophisticated tumorstromal microenvironment. This merits further investigation using co-culture between malignant epithelial cells, fat and vascular and inflammatory cells as this likely to influence response to therapy. Additionally, in vivo studies employing patient-derived xenograft model would be very informative in promoting these novel ideas toward clinical trials. Recognizing the known complication of translating scientific discovery to clinical benefit, the question of whether inhibition of IKK $\alpha$ is a valuable therapeutic strategy in ER-positive breast cancer will have to await more positive results from other model systems and also the further development of additional IKK $\alpha$ inhibitors with minimal potential toxicity and highly bioavailable.

\section{Future perspectives}

In the last few years, there have been significant shifts in the attitudes toward the use of estrogen in clinic. Estrogen exhibits a broad range of functions that regulates cell proliferation and homeostasis in many tissues. Despite beneficial estrogen functions, sustained estrogenic exposure increases the risk and/or the progression of various cancers, including those of the breast, endometrium and ovary $^{15}$. The International Agency for Research on Cancer (IARC) has listed estrogen as known human carcinogen ${ }^{16}$. Now, the success of the combination of E2 and BAY will certainly become an "accelerator" to the alternative use of estrogen in treating cancers and we expect to see more positive pre-clinical and/or clinical results on $\mathrm{BAY}$ or other IKK $\alpha$ inhibitors in ER-positive hormone responsive cancers in the near future.

\section{Author contributions}

Conceived and designed the Figure: WZ XZ. Wrote the paper: WZ XZ.

\section{Competing interests}

No competing interests were disclosed.

\section{Grant information}

This work was partially supported by US Department of Defense pre-doctoral grant W81XWH-11-1-0097 (W.Z.).

The funders had no role in study design, data collection and analysis, decision to publish, or preparation of the manuscript.

\section{Acknowledgments}

The authors thank laboratory members for helpful discussions. The authors thank Drs. S. L. Young and P. Saunders for their constructive comments during the post-publication peer review process. Readers are encouraged to read the reviewers' comments for relevant literature and discussions on whether BAY is also effective in endocrine-resistant breast cancers. 
1. Beatson GT: On treatment of inoperable cases of carcinoma of the mamma: suggestions for a new method of treatment with illustrative cases. Lancet. 1896; 148(3802): 104-7.

Publisher Full Text

2. Haddow A, Watkinson JM, Paterson E, et al.: Influence of Synthetic Oestrogens on Advanced Malignant Disease. Br Med J. 1944; 2(4368): 393-8. PubMed Abstract | Publisher Full Text | Free Full Text

3. Huggins C, Bergenstal DM: Effect of Bilateral Adrenalectomy on Certain Human Tumors. Proc Natl Acad Sci U S A. 1952; 38(1): 73-6. PubMed Abstract | Publisher Full Text | Free Full Text

4. Prentice RL, Anderson GL: The women's health initiative: lessons learned. Annu Rev Public Health. 2008; 29: 131-50. PubMed Abstract | Publisher Full Text

5. Musgrove EA, Caldon CE, Barraclough J, et al:: Cyclin D as a therapeutic target in cancer. Nat Rev Cancer. 2011; 11(8): 558-72. PubMed Abstract | Publisher Full Text

6. Caldon $\mathrm{CE}$, Musgrove EA: Distinct and redundant functions of cyclin E1 and cyclin E2 in development and cancer. Cell Div. 2010; 5: PubMed Abstract | Publisher Full Text | Free Full Text

7. Zhou W, Srinivasan S, Nawaz Z, et al:: ER $\alpha$, SKP2 and E2F-1 form a feed forward loop driving late $\mathrm{ER} \alpha$ targets and G1 cell cycle progression. Oncogene. 2014; 33(18): 2341-53.

PubMed Abstract | Publisher Full Text

8. Sun J, Zhou W, Kaliappan K, et al.: ER $\alpha$ phosphorylation at Y537 by Src triggers E6-AP-ER $\alpha$ binding, ER $\alpha$ ubiquitylation, promoter occupancy, and target gene expression. Mol Endocrinol. 2012; 26(9): 1567-77. expression. Mol Endocrinol. 2012; 26(9): 1567-77.
PubMed Abstract | Publisher Full Text | Free Full Text

9. Kato $\mathrm{S}$, Endoh $\mathrm{H}$, Masuhiro $\mathrm{Y}$, et al: Activation of the estrogen recepto through phosphorylation by mitogen-activated protein kinase. Science. 1995;
270(5241): 1491-4

PubMed Abstract | Publisher Full Text

10. Ariazi EA, Cunliffe HE, Lewis-Wambi JS, et al.: Estrogen induces apoptosis in estrogen deprivation-resistant breast cancer through stress responses as identified by global gene expression across time. Proc Natl Acad Sci U S A 2011; 108(47): 18879-86.

PubMed Abstract | Publisher Full Text | Free Full Text

11. Perillo B, Di Santi A, Cernera G, et al:: Phosphorylation of $\mathbf{H} 3$ serine $\mathbf{1 0}$ by IKK governs cyclical production of ROS in estrogen-induced transcription and ensures DNA wholeness. Cell Death Differ. 2014.

PubMed Abstract | Publisher Full Text

12. Park KJ, Krishnan V, O'Malley BW, et al.: Formation of an IKKalpha-dependent transcription complex is required for estrogen receptor-mediated gene activation. Mol Cell. 2005; 18(1): 71-82.

PubMed Abstract | Publisher Full Tex

13. Rea S, Eisenhaber F, O'Carroll D, et al.: Regulation of chromatin structure by site-specific histone H3 methyltransferases. Nature. 2000; 406(6796): 593-599. PubMed Abstract | Publisher Full Text

14. Perillo B, Ombra MN, Bertoni A, et al:: DNA oxidation as triggered by $\mathrm{H} 3 \mathrm{~K} 9 \mathrm{me} 2$ demethylation drives estrogen-induced gene expression. Science. 2008; 319(5860): 202-206

PubMed Abstract | Publisher Full Text

15. Zhou W, Slingerland JM: Links between oestrogen receptor activation and proteolysis: relevance to hormone-regulated cancer therapy. Nat Rev Cancer. 2014; 14(1): 26-38.

PubMed Abstract | Publisher Full Tex

16. IARC Working Group on the Evaluation of Carcinogenic Risks to Humans. Combined estrogen-progestogen contraceptives and combined estrogen-progestogen menopausal therapy. IARC Monogr Eval Carcinog Risks Hum. 2007; 91: 1-528. PubMed Abstract 


\section{Open Peer Review}

\section{Current Peer Review Status:}

\section{Version 2}

Reviewer Report 24 November 2014

https://doi.org/10.5256/f1000research.5741.r6796

(C) 2014 Young S. This is an open access peer review report distributed under the terms of the Creative Commons Attribution License, which permits unrestricted use, distribution, and reproduction in any medium, provided the original work is properly cited.

\section{Steven L Young}

Department of Obstetrics \& Gynecology, University of North Carolina at Chapel Hill, Chapel Hill, NC, USA

The authors have addressed all my concerns.

Competing Interests: No competing interests were disclosed.

I confirm that I have read this submission and believe that I have an appropriate level of expertise to confirm that it is of an acceptable scientific standard.

Reviewer Report 13 October 2014

https://doi.org/10.5256/f1000research.5741.r6389

(C) 2014 Saunders $\mathbf{P}$. This is an open access peer review report distributed under the terms of the Creative Commons Attribution License, which permits unrestricted use, distribution, and reproduction in any medium, provided the original work is properly cited.

\section{Philippa Saunders}

Center for Reproductive Health, University of Edinburgh, Edinburgh, UK

The authors have provided responses to my original comments and incorporated some changes into their manuscript which have improved it.

\section{Suggestions for minor modifications:}

Section entitled 'Challenges'

The authors state that estrogen regulates the proliferation and development of tissues expressing 
estrogen receptors and that 'ER' is expressed in steroid--- responsive female tissues such as the ovary, endometrium and breast. The authors further state 'Thus, estrogen is mitogenic for cultured ER positive breast cancer cell lines."

The authors need to amend this paragraph to make it clear that there are two estrogen receptor genes both of which are expressed in breast cancers ${ }^{1-3}$. Studies on knockout mice have highlighted that expression of the ERa isoform has been identified as critically important to cell proliferation in the uterus and breast ${ }^{4,5}$. Studies in breast cancer cell lines have highlighted the importance of ERa in both up and down-regulation of cell proliferation and this remains a very active area of research ${ }^{6,7}$. The authors are encouraged to amend the text of this section changing 'ER' to ERa to make better sense of comments made in the section entitled 'Research Breakthrough'.

\section{References}

1. Gustafsson JA, Warner M: Estrogen receptor beta in the breast: role in estrogen responsiveness and development of breast cancer.J Steriod Biochem Mol Biol. 2000; 74 (5): 245-248 PubMed Abstract | Publisher Full Text | Reference Source

2. Speirs V, Parkes AT, Kerin MJ, Walton DS, et al.: Coexpression of estrogen receptor alpha and beta: poor prognostic factors in human breast cancer. Cancer Res. 1999; 59 (3): 525-528 PubMed Abstract | Reference Source

3. Shaaban AM, Green AR, Karthik S, Alizadeh Y, et al.: Nuclear and cytoplasmic expression of ERbeta1, ERbeta2, and ERbeta5 identifies distinct prognostic outcome for breast cancer patients. Clin Cancer Res. 2008; 14 (16): 5228-55235 PubMed Abstract | Publisher Full Text | Reference Source

4. Hewitt SC, Korach KS: Oestrogen receptor knockout mice: roles for oestrogen receptors alpha and beta in reproductive tissues.Reproduction. 2003; 125 (2): 143-149 PubMed Abstract | Publisher Full Text | Reference Source

5. Couse JF, Korach KS: Estrogen receptor null mice: what have we learned and where will they lead us?. Endrocr Rev. 1999; 20 (3): 358-417 PubMed Abstract | Reference Source

6. Stender JD, Frasor J, Komm B, Chang KC, et al.: Estrogen--regulated gene networks in human breast cancer cells: involvement of E2F1 in the regulation of cell proliferation. Mol Endocrinol. 2007; 21 (9): 2112-2123 PubMed Abstract | Publisher Full Text | Reference Source

7. Rosell M, Nevedomskaya E, Stelloo S, Nautiyal J, et al.: Complex Formation and Function of Estrogen Receptor alpha in Transcription Requires RIP140. Cancer Res. 2014; 74 (19): 5469-5479 PubMed Abstract | Publisher Full Text | Reference Source

Competing Interests: No competing interests were disclosed.

I confirm that I have read this submission and believe that I have an appropriate level of expertise to confirm that it is of an acceptable scientific standard.

\section{Version 1}

Reviewer Report 22 September 2014 
https://doi.org/10.5256/f1000research.5075.r6196

(C) 2014 Saunders P. This is an open access peer review report distributed under the terms of the Creative Commons Attribution License, which permits unrestricted use, distribution, and reproduction in any medium, provided the original work is properly cited.

\section{Philippa Saunders}

Center for Reproductive Health, University of Edinburgh, Edinburgh, UK

New ideas about the way oestrogens might affect the growth, differentiation and functional development of cancers, including those of the breast, are always welcome. The authors' Opinion Article questions whether giving oestrogens (rather than the more common anti-oestrogens) may merit exploration as an alternative treatment for breast cancers when provided in combination with agents that alter inflammatory signalling pathways. A limitation of the commentary is that it has focused on data from studies using breast cancer cell lines such as the MCF-7 cells cited in the studies by the Perillo group ${ }^{1-3}$. A limitation of all studies using tissue-culture adapted cell lines such as MCF-7 is that they do not reflect the genomic heterogeneity we now appreciate exists in different breast tumours ${ }^{4}$, only a proportion of which are considered classically activated by oestrogens because they are ER alpha positive. In spite of these reservations the authors do raise some interesting points.

Firstly, they highlight the potential for inflammatory mediators such as those that activate the NFK $B$ signalling pathway as targets for therapies in breast cancer treatment. One example provided is the data from the Perillo group, reporting that inhibition of IKKa kinase specific inhibitor BAY117082 might be beneficial in switching the effects of oestrogens from anti- to pro-apoptotic. These studies are in agreement with those from a number of other authors claiming that combination therapies are likely to be beneficial in treatment of this malignancy. Notably, there is an interesting paper by Biswas et al. published in $2004{ }^{5}$ which examines how NFkB activation in breast cancer specimens might have a role in cell proliferation and apoptosis. Notably, in the Biswas paper, they report results suggesting that activated NFKB is predominantly detected in ER negative rather than ER positive breast tumours. This paper, as well as the recent genomic proflling of breast cancers from 2000 patients ${ }^{4}$ highlights the importance of considering the both the immediate microenvironment of the tumour as well as the adjacent non-tumour tissue. Notably, in considering how oestrogen therapy might be utilised, it is important to take into account the hormonal status of the woman (pre or post menopausal) as well as the compelling data that has demonstrated intra-tissue oestrogen biosynthesis in fat and other cells close to the malignant epithelial cells in situ ${ }^{6}$. A paper that has just appeared in the Journal of Clinical Endocrinology and Metabolism by Savolainen-Peltonen and colleagues ${ }^{7}$ is particularly relevant. In this paper, the authors compared the metabolic pathways producing active oestradiol in breast subcutaneous adipose tissue of postmenopausal women with and without cancer, and these showed there were differences depending on whether the adipose tissue was proximal or distal to a tumour. If the tumour is already bathed in high concentrations of oestrogen either from the periphery or local biosynthesis then addition of more ligand is unlikely to be effective.

The local inflammatory environment of the tumour is an important factor in tumour progression and it is influenced by activation of NFKB activity leading to production of inflammatory mediators such as TNFa, IL-1 $\beta$ and prostaglandin E2 from adipocyteassociated macrophages and COX-2 inhibitors have been cited as effective in reducing recurrence of cancer ${ }^{8}$. Local increases in 
inflammatory mediators in turn stimulate adipocyte aromatase expression/activity and hence oestradiol production ${ }^{9}$ that may be particularly relevant to obese women ${ }^{9,10}$. Thus, when considering suppression of NFKB activity in combination therapy there may be many contextdependent impacts on the tumour microenvironment to consider.

The role of NFkB activation as a regulator of inflammatory signalling is particularly important to consider in the context of endocrine resistant breast cancer which cannot be addressed using MCF-7 cells. A new paper in Molecular Cellular Endocrinology by Litchfield et al. ${ }^{11}$ notes that regulation of endocrine-resistant breast cancer cells may also be mediated by other transcription factors such as COUPTFII. So the keys questions to be addressed in considering the value of the future prospective advanced within this Opinion piece are the following:

1. Are studies in isolated cell lines such as the one described really relevant when it comes to translating new therapies into practice?

2. Is inhibition of inflammatory mediators such as that using the BAY compound really most effective in cells that are not actually estrogen responsive?This merits further investigation.

3. Finally, how can we move forward with the field?

In our opinion, an excellent way to advance these studies would be to conduct further investigations using methods which better reflect the microenvironment of an intact tumour in situ, this should include studies on the interplay between malignant epithelial cells, fat and vascular and inflammatory cells as this likely to influence response to therapy and it cannot be under-estimated that the individual responses to oestrogens by these different cell types may vary considerably. Examples of such studies currently include 3 being explored in the context of breast cancer, including organoids, tissue slices or xenografts. These approaches are more likely than studies in MCF-7 cells to inform choice of new combination therapies for testing in clinical trials; oestrogen combined with NFkB inhibition should be tested in these systems ${ }^{12-14}$.

\section{References}

1. Perillo B, Di Santi A, Cernera G, Ombra MN, et al.: Phosphorylation of H3 serine 10 by IKKa governs cyclical production of ROS in estrogen-induced transcription and ensures DNA wholeness. Cell Death Differ. 2014; 21 (9): 1503-1503 PubMed Abstract | Free Full Text | Publisher Full Text | Reference Source

2. Perillo B, Di Santi A, Cernera G, Ombra MN, et al.: Nuclear receptor-induced transcription is driven by spatially and timely restricted waves of ROS: The role of Akt, IKKa, and DNA damage repair enzymes.Nucleus. 2014; 5 (5). PubMed Abstract | Publisher Full Text | Reference Source 3. Perillo B, Ombra MN, Bertoni A, Cuozzo C, et al.: DNA oxidation as triggered by H3K9me2 demethylation drives estrogen-induced gene expression.Science. 2008; 319 (5860): 202-206 PubMed Abstract | Publisher Full Text | Reference Source

4. Curtis C, Shah SP, Chin SF, Turashvili G, et al.: The genomic and transcriptomic architecture of 2,000 breast tumours reveals novel subgroups. Nature. 2012; 486 (7403): 346-352 PubMed Abstract | Free Full Text | Publisher Full Text | Reference Source

5. Biswas DK, Shi Q, Baily S, Strickland I, et al.: NF-kappa B activation in human breast cancer specimens and its role in cell proliferation and apoptosis. Proc Natl Acad Sci U S A. 2004; 101 (27): 10137-10142 PubMed Abstract | Free Full Text | Publisher Full Text | Reference Source 
6. Simpson HW, Candlish W, Pauson AW, McArdle CS, et al.: Genesis of breast cancer is in the premenopause. Lancet. 1988; 2 (8602): $74-76$ PubMed Abstract | Reference Source 7. Savolainen-Peltonen $\mathrm{H}$, Vihma V, Leidenius M, Wang F, et al.: Breast Adipose Tissue Estrogen Metabolism in Postmenopausal Women with or without Breast Cancer. J Clin Endocrinol Metab. 2014. PubMed Abstract | Reference Source

8. Bowers LW, Maximo IX, Brenner AJ, Beeram M, et al.: NSAID Use Reduces Breast Cancer Recurrence in Overweight and Obese Women: Role of Prostaglandin-Aromatase Interactions. Cancer Res. 2014; 74 (16): 4446-4457 PubMed Abstract | Publisher Full Text | Reference Source 9. Subbaramaiah K, Hudis C, Chang SH, Hla T, et al.: EP2 and EP4 receptors regulate aromatase expression in human adipocytes and breast cancer cells. Evidence of a BRCA1 and p300 exchange.J Biol Chem. 2007; 283 (6): 3433-3444 PubMed Abstract | Publisher Full Text | Reference Source 10. Subbaramaiah K, Howe LR, Port ER, Brogi E, et al.: HER-2/neu status is a determinant of mammary aromatase activity in vivo: evidence for a cyclooxygenase-2-dependent mechanism. Cancer Res. 2006; 66 (10): 5504-5511 PubMed Abstract | Publisher Full Text | Reference Source 11. Litchfield LM, Appana SN, Datta S, Klinge CM: COUP-TFII inhibits NFkappaB activation in endocrine-resistant breast cancer cells. Mol Cell Endocrinol. 2014; 382 (1): 358-367 PubMed Abstract | Publisher Full Text | Reference Source

12. Walsh AJ, Cook RS, Sanders ME, Aurisicchio L, et al.: Quantitative optical imaging of primary tumor organoid metabolism predicts drug response in breast cancer.Cancer Res. 2014; 74 (18): 5184-5194 PubMed Abstract | Free Full Text | Publisher Full Text | Reference Source 13. Sun X, Mao Y, Wang J, Zu L, et al.: IL- 6 secreted by cancer-associated fibroblasts induces tamoxifen resistance in luminal breast cancer. Oncogene. 2014; 33 (35): 4450 PubMed Abstract | Publisher Full Text | Reference Source

14. Holliday DL, Moss MA, Pollock S, Lane S, et al.: The practicalities of using tissue slices as preclinical organotypic breast cancer models. J Clin Pathol. 2013; 66 (3): 253-255 PubMed Abstract | Reference Source

Competing Interests: No competing interests were disclosed.

\section{I confirm that I have read this submission and believe that I have an appropriate level of expertise to confirm that it is of an acceptable scientific standard, however I have significant reservations, as outlined above.}

Reader Comment ( ) 25 Sep 2014

Wen Zhou, Case Western Reserve University, USA

The observations made by Dr. Saunders were very pertinent and allowed us to alter the manuscript in several key points. Below we address each one of the reviewer comments. We hope to have provided all the information needed regarding the work submitted and that the manuscript is now suitable for publishing and archiving. Alterations were signalized in the text.

\section{Responses:}

1. "A limitation of the commentary is that it has focused on data from studies using breast cancer cell lines such as the MCF-7 cells cited in the studies by the Perillo group. A limitation of all studies using tissue-culture adapted cell lines such as MCF-7 is that they do not reflect the genomic heterogeneity we now appreciate exists in 
different breast tumours, only a proportion of which are considered classically activated by oestrogens because they are ER alpha positive ... Are studies in isolated cell lines such as the one described really relevant when it comes to translating new therapies into practice?"

We thank Dr. Saunders for her comment. Perillo used an experimental approach to evaluate the molecular interaction of both ER and other signaling pathways in MCF-7 cells, as described in many journal publications (Garcia et al., 1992; Planas-Silva et al., 1999; Sun et al., 2012). In these works an evaluation of the biological effect of the molecular interaction was assessed as Perillo group performed in their work. Thus, we believe Perillo's cell line based studies are meaningful and relevant to find novel targets in hormone responsive cancers. Still, we have altered the manuscript, avoiding the reference to other proportion of breast tumors which are not so responsive to hormone therapy. Although it has been previously reported that ER positive cancers make up to two thirds of newly diagnosed breast cancer cases, we agree with Dr. Saunders that it is important to appreciate the highly existed heterogeneity under the name of breast cancer, to take into account the hormone status of women, and to better understanding the tumor-stromal microenvironment.

2. "Notably, there is an interesting paper by Biswas et al. published in 2004 which examines how NFkB activation in breast cancer specimens might have a role in cell proliferation and apoptosis. Notably, in the Biswas paper, they report results suggesting that activated NFKB is predominantly detected in ER negative rather than ER positive breast tumours... Is inhibition of inflammatory mediators such as that using the BAY compound really most effective in cells that are not actually estrogen responsive? "

We agree with Dr. Saunders that activated NFKB is predominantly detected in ER negative rather than ER positive breast tumors. Perillo's study we referred in our opinion article also support this point, as "BAY (IKKa inhibitor) only" induced more apoptosis in MDA-MB-231 (ER-negative) cells compared with MCF-7 in their Figure S1C. However, the point to make here, as shown in original Perillo paper, is that estradiol combined with BAY has been more potent in inducing apoptosis in ER positive cells compared with each agent alone in either cell lines. Perillo's study revealed the previously hidden pro-apoptotic property of estrogen in physiological concentration range. On this stand, it inspired us to write this opinion article, and we think it was an interesting observation and worth attracting more attention as well as the warm discussions we have thus far achieved.

3. "Finally, how can we move forward with the field? In our opinion, an excellent way to advance these studies would be to conduct further investigations using methods which better reflect the microenvironment of an intact tumour in situ, this should include studies on the interplay between malignant epithelial cells, fat and vascular and inflammatory cells as this likely to influence response to therapy and it cannot be under-estimated that the individual responses to oestrogens by these different cell types may vary considerably. Examples of such studies currently include 3 being explored in the context of breast cancer, including organoids, tissue slices or 
xenografts. These approaches are more likely than studies in MCF-7 cells to inform choice of new combination therapies for testing in clinical trials; oestrogen combined with NFkB inhibition should be tested in these systems."

We thank Dr. Saunders for her comments and have changed part of our content according to her suggestion.

Competing Interests: No competing interests were disclosed.

Reviewer Report 11 August 2014

https://doi.org/10.5256/f1000research.5075.r5459

(C) 2014 Young S. This is an open access peer review report distributed under the terms of the Creative Commons Attribution License, which permits unrestricted use, distribution, and reproduction in any medium, provided the original work is properly cited.

\section{Steven L Young}

Department of Obstetrics \& Gynecology, University of North Carolina at Chapel Hill, Chapel Hill, NC, USA

In this opinion manuscript, Zhou and Zhu highlight recent research that suggests estrogen can act on opposing signaling pathways to either promote proliferation or cell death in breast cancer cells and, further, that the signaling can be biased toward cell death by inhibition of IKKa action. The manuscript is thought provoking and timely and the argument is logical and generally wellconstructed. The title is eye-catching and appropriate. The figure is attractive and highlights the key point of the manuscript. If the areas of concern (below) are addressed, the conclusions will be justified by the argument presented.

I have four areas of concern:

1. The manuscript is marred by frequent grammatical and English language usage errors as well as occasional typographic errors. While readable, it is sometimes difficult to determine the precise meaning of the authors' statements.

2. In the introduction, the authors state that estrogen, in combination with IKKa, can induce breast cancer apoptosis. However, it is IKKa inhibition that is used, suggesting that it is the absence of IKKa effect that is important - this should be clarified as currently the penultimate sentence of the introduction paragraph appears to be contradicted by the sentence following.

3. The authors propose that IKKa inhibition has great promise for clinical use, but fail to remark on factors that would be important for feasibility of such therapy (see below):

1. If IKKa were inhibited systemically, would apoptosis be largely limited to the cancer 
cells? What about other estrogen target tissues?

2. Are there known toxicities of BAY or other IKKa inhibitors that would need to be considered?

3. Are the concentrations of estradiol and IKKa inhibitor necessary to induce cell death achievable in humans?

4. Are the concentrations of estradiol required for induction of cell death in the normal pre-menopausal range, or are these pharmacological levels: important implications for treatment of women with functioning ovaries and for the thrombogenic side effects of estrogen therapy, which are dose-related.

4. The abstract does not effectively summarize the manuscript.

Competing Interests: No competing interests were disclosed.

I confirm that I have read this submission and believe that I have an appropriate level of expertise to confirm that it is of an acceptable scientific standard, however I have significant reservations, as outlined above.

Reader Comment ( ) 25 Sep 2014

Wen Zhou, Case Western Reserve University, USA

"In this opinion manuscript, Zhou and Zhu highlight recent research that suggests estrogen can act on opposing signaling pathways to either promote proliferation or cell death in breast cancer cells and, further, that the signaling can be biased toward cell death by inhibition of IKKa action. The manuscript is thought provoking and timely and the argument is logical and generally well-constructed. The title is eye-catching and appropriate. The figure is attractive and highlights the key point of the manuscript. If the areas of concern (below) are addressed, the conclusions will be justified by the argument presented."

We thank Dr. Young for his supportive and encouraging comments.

\section{Major concerns:}

1. "The manuscript is marred by frequent grammatical and English language usage errors as well as occasional typographic errors. While readable, it is sometimes difficult to determine the precise meaning of the authors' statements."

We made the corrections.

2. "[T]he authors state that estrogen, in combination with IKKa, can induce breast cancer apoptosis. However, it is IKKa inhibition that is used, suggesting that it is the absence of IKKa effect that is important - this should be clarified as currently the penultimate sentence of the introduction paragraph appears to be contradicted by the sentence following."

We agree with Dr. Young and we have made appropriate changes. 
3. "The abstract does not effectively summarize the manuscript."

We fully agree with Dr. Young. We re-wrote the abstract part to give more accurate summary of the content and include several recent related literature. We made also changes to the discussion part in accordance to these new findings.

\section{Additional concerns:}

1. "If IKKa were inhibited systemically, would apoptosis be largely limited to the cancer cells? What about other estrogen target tissues?"

Though the toxicity of IKKa inhibition is unknown, IKKa-mediated activity has been implicated in cerntain cancers. In addition, IKKa has been reported to enhance RelA/p65 activity, which protein was implicated to drive oncogenic transformations. Like selective ER modulators (SERM) therapy, this therapy may have adverse effect on other estrogen target tissues. This merits further investigation.

2. "Are there known toxicities of BAY or other IKKa inhibitors that would need to be considered?"

The toxicities of BAY11-7082 (BAY) is unknown. Most IKK inhibitors are highly selective for $\beta$ isoform, and there are few IKKa-specific inhibitors. Further investigation on its toxicity is highly needed.

3. "Are the concentrations of estradiol and IKKa inhibitor necessary to induce cell death achievable in humans?"

The concentration of estradiol used in Perillo's study is $10 \mathrm{nM}$, and IKKa inhibitor BAY used is $20 \mu \mathrm{M}$. The same concentration of estradiol is achievable in humans. The human pharmacokinetic data for BAY is not available, though BAY is also shown to be effective when used in $10 \mu \mathrm{M}$ or even $1 \mu \mathrm{M}$ concentrations (Che et al., 2014; Zhao et al., 2014; Jung et al., 2014).

4. "Are the concentrations of estradiol required for induction of cell death in the normal pre-menopausal range, or are these pharmacological levels: important implications for treatment of women with functioning ovaries and for the thrombogenic side effects of estrogen therapy, which are dose-related."

The concentrations of estradiol required when used together with BAY for the induction of cell death is $10 \mathrm{nM}$, which is within the normal premenopausal range. We agree with Dr. Young and also another reviewer Dr. Philippa Sauders that it is important to take into account the different hormonal effect on pre- or postmenopausal women, and the dose-related thrombogenic side effect of estrogen.

Competing Interests: No competing interests were disclosed. 
The benefits of publishing with F1000Research:

- Your article is published within days, with no editorial bias

- You can publish traditional articles, null/negative results, case reports, data notes and more

- The peer review process is transparent and collaborative

- Your article is indexed in PubMed after passing peer review

- Dedicated customer support at every stage

For pre-submission enquiries, contact research@f1000.com 